\title{
The effect of out-of-pocket costs and financial rewards in a discrete choice experiment: an application to lifestyle programs
}

\author{
Johanna O P Wanders ${ }^{1,2^{*}}$, Jorien Veldwijk ${ }^{1,2}, \mathrm{G}$ Ardine de Wit ${ }^{1,2}$, Huberta E Hart ${ }^{3}$, Paul F van Gils ${ }^{1}$ \\ and Mattijs S Lambooij
}

\begin{abstract}
Background: Both out-of-pocket costs and financial rewards can be used to influence health related behavior. However, it is unclear which of these two has a larger effect on health related behavior. The aim of this study was to explore the possible difference in effect size between out-of-pocket costs and financial rewards on the willingness of diabetes mellitus type 2 (DM2) patients to participate in a lifestyle program.

Methods: A discrete choice experiment (DCE) questionnaire was sent to 767 DM2 patients in a geographically defined area (De Leidsche Rijn, Utrecht) in The Netherlands and completed by 206 of them. The questionnaire comprised of 18 choice tasks of which 9 contained a financial reward for lifestyle program completion, while the other 9 included out-of-pocket costs for program participation. In a second version of the questionnaire, the order of out-of-pocket cost and financial reward choice tasks was counterbalanced to reduce bias with respect to the position (first or second) of the two types of choice tasks. Panel-mixed-multinomial-logit models were used for data analysis.

Results: Increasing out-of-pocket costs were associated with a decreasing willingness to participate in a lifestyle program and, contrary to our expectations, increasing financial rewards were also associated with a decreasing willingness to participate in a lifestyle program. In addition, this willingness to participate changed to the same extent for both increasing out-of-pocket costs and increasing financial rewards.

Conclusions: As expected, increasing out-of-pocket costs may prevent people from deciding to participate in a lifestyle program. However, offering a financial reward to persuade people to participate in a lifestyle program, may result in decreasing willingness to participate in a lifestyle program as well.
\end{abstract}

Keywords: Out-of-pocket costs, Financial rewards, Lifestyle programs, Discrete choice experiment, Willingness to participate, Diabetes mellitus type 2

\section{Background}

Out-of-pocket costs and financial rewards are used in an attempt to change people's behavior, including health related behavior. For instance, out-of-pocket costs like taxes on cigarettes are used to reduce smoking and have been shown to be reasonably successful [1-3]. Examples

\footnotetext{
*Correspondence: j.o.p.wanders@umcutrecht.nl

${ }^{1}$ National Institute for Public Health and the Environment, Centre for Prevention and Health Services Research, PO Box 1 (Internal postal code: 101), 3720 BA Bilthoven, The Netherlands

2Division: Julius Center for Health Sciences and Primary Care, University Medical Center Utrecht, Huispost Str. 6.131, Postbus 85500, 3508 GA Utrecht, The Netherlands

Full list of author information is available at the end of the article
}

of financial rewards that are used in an attempt to improve lifestyle include covering membership costs for physical activity programs and rewarding people for performing healthy behavior [4-7]. The use of costs and financial rewards is premised on the notion that humans are rational actors who will consider advantages and disadvantages of the possible options and then choose the option that is best for their (financial) situation. Overall, out-of-pocket costs are thought to have an inhibitory effect on behavior, while financial rewards are thought to stimulate behavior. However, the impact of either outof-pocket costs or financial rewards on behavior might not be the same. According to Kahneman and Tversky, 
on average people tend to be aversive to losses $[8,9]$. This loss aversion implies that losses and disadvantages have a greater impact on the preferences of individuals than gains and advantages of similar size [9].

A similar response structure may occur when people receive either a financial reward or have to pay at the moment they have to decide whether or not they want to participate in a lifestyle intervention. When accounting for loss aversion, while holding everything else constant, asking potential participants for a financial contribution (out-ofpocket costs) is expected to have a stronger negative effect on their willingness to participate compared to the positive effect of receiving a financial reward of a similar size.

Much research has been conducted on the effect of costs and financial rewards on the outcome of intervention programs (weight loss, physical activity, smoking cessation etc.). These studies show that incentives are effective in general [10-14]. However, participants of these studies are often carefully selected volunteers and they may consequently have a greater motivation to change their behavior than a random selection from the target population. Therefore, we chose not to study the effects of out-of-pocket costs and financial rewards among participants in a lifestyle program, but among a population that is eligible to participate in a lifestyle program. Subsequently, we did not focus on the effect of out-of-pocket costs and financial rewards on the outcome of a lifestyle program, but studied its effect on the preceding step, namely, the willingness to participate in a lifestyle program or not.

The aim of this study is to explore the possible difference in the impact of out-of-pocket costs and financial rewards on the willingness of diabetes mellitus type 2 (DM2) patients to participate in a lifestyle intervention program. This is determined in a discrete choice experiment (DCE) where the stated preferences elicited from scenarios including only financial rewards are compared to the preferences elicited from scenarios including only out-of-pocket costs.

\section{Methods}

\section{Participants and recruitment}

The study population comprised of all DM2 patients of four health care centers with over 20 general practitioners (GPs) in a geographically defined area (De Leidsche Rijn, Utrecht) in The Netherlands. All patients in the study population were primarily treated in primary care. Mentally and/or terminally ill DM2 patients were excluded. In total 767 patients were asked to complete the DCE questionnaire, that was sent along with an accompanying letter from the health care centres. After 3 weeks, a reminder was sent to the patients who had not returned the questionnaire yet. Patients who completed the questionnaire received a voucher of 7.50 euro.
Patient data on ethnicity, gender, age, Hba1C, body mass index (BMI) and use of antidiabetic drugs were retrieved from the Electronic Medical Records by the patient's general practitioner, and added to the research database anonymously, without further patient identifiers. According to The Dutch National Ethics Board (Central Committee on Research involving Human Subjects) formal testing by a medical ethical committee was not necessary as T2DM patients only had to complete an anonymous questionnaire once, which is in accordance with the guidelines laid down in the Declaration of Helsinki.

\section{Discrete choice experiment}

Discrete Choice Experiments (DCE's) are used more and more in public health research to estimate the willingness of people to participate in interventions or medical treatments and to provide information about the components of that program that are important for people in their decision whether or not to participate $[15,16]$. The DCE methodology is based on the Random Utility Theory and assumes that any intervention or medical treatment can be described by its characteristics (i.e. attributes; such as costs). The individual's preference for an intervention or treatment is dependent on the levels (e.g., 75 or 100 euro) of those attributes $[15,16]$. By varying the levels of the attributes, different scenarios are constructed. Respondents are provided with at least two scenarios (i.e.,choice tasks) simultaneously, they then have to choose the scenario they prefer most. Each respondent is asked to complete a series of such choice tasks. The relative importance of the different attributes and levels can be estimated, providing information on the elements of the intervention that are most important in deciding whether or not to participate in the intervention.

\section{Attributes and levels}

A DCE consists of several choice tasks and in this study each choice task comprised of two hypothetical scenarios (unlabelled) and an opt-out option (see Figure 1 for a choice task example). The opt-out option was included because it most closely reflects the situation that patients are in, i.e. voluntary participation in lifestyle programs. Each scenario is described in terms of attributes of the lifestyle program. Each attribute has several levels. To determine the attributes and levels in this study, a stepwise manner was used. First, a literature study was done to compose a list of barriers and facilitators of DM2 patients for participating in a lifestyle intervention [17-27]. Then, the obtained list of barriers and facilitators was discussed using expert interviews $(n=3)$. Finally, 4 focus groups with DM2 patients $(n=24)$ were conducted [28] to ensure that the most important attributes for the decision-making process of DM2 patients were included 
Imagine that your general practitioner recommends you to participate in a lifestyle intervention program for 3 to 6 months. In which situation would you prefer to participate, in situation 1 or situation 2? If you do not want to participate in either of these lifestyle programmes, you can tick the option "None".

\begin{tabular}{|c|c|c|c|}
\hline & Situation 1 & Situation 2 & None \\
\hline Menu schedule & $\begin{array}{l}\text { Flexible } \\
\text { (you composed this schedule) }\end{array}$ & $\begin{array}{l}\text { General } \\
\text { (with information about diet and } \\
\text { examples of recipes) }\end{array}$ & None \\
\hline $\begin{array}{l}\text { Physical activity } \\
\text { schedule }\end{array}$ & $\begin{array}{l}\text { General } \\
\text { (with information about physical } \\
\text { activity and examples of } \\
\text { exercises) }\end{array}$ & $\begin{array}{l}\text { Elaborate } \\
\text { (this schedule is composed for } \\
\text { you and tailored to your needs) }\end{array}$ & None \\
\hline Consult structure & Individual & In a group with 5 other people & None \\
\hline Expected outcome & $\begin{array}{l}5 \mathrm{~kg} \text { weight loss and feeling } \\
\text { fitter }\end{array}$ & $\begin{array}{l}10 \mathrm{~kg} \text { weight loss and feeling } \\
\text { fitter }\end{array}$ & None \\
\hline Financial reward & 150 euro & 150 euro & 0 euro \\
\hline \multicolumn{2}{|l|}{ I would rather } & & \\
\hline \multicolumn{4}{|l|}{ Tick the situation that } \\
\hline
\end{tabular}

Figure 1 Example of a choice task. Figure 1 shows an example of a choice task with a reward for the "money" attribute. Participants choose the situation they most prefer or choose 'none' (opt-out) if they do not want to participate in either of the two situations.

and that the right levels were chosen for each attribute. This resulted in the selection of five attributes for the current DCE: money, menu schedule, physical activity schedule, consult structure and expected outcome. These attributes are the same as the attributes described by Veldwijk et al. [29], since the development of the DCE in this study is based on the same literature study, expert interviews and focus groups with DM2 patients as the DCE described by Veldwijk et al. Each attribute contained three levels, except for the "money" attribute that contained 6 levels (Table 1), either representing financial rewards (75, 150 or 225 euro) for completing the entire program that lasts 3 to 6 months or representing out-of-pocket costs ( 75,150 or 225 euro) for participating in the lifestyle program. Veldwijk et al. used only three levels for the "money" attribute, namely three out-of-pocket costs levels. The maximum amount for the "money" attribute level was based on the compulsory level of co-payment within Dutch health insurance, for any type of health services used in 2012. Therefore we assume that the magnitude of 
Table 1 Attributes and levels that were included in the DCE and coding used for data-analysis

\begin{tabular}{|c|c|c|}
\hline Attribute & Levels & Coding \\
\hline \multirow[t]{3}{*}{ Menu schedule } & Flexible (ref) & \\
\hline & General & \\
\hline & Elaborate & \\
\hline \multirow[t]{3}{*}{ Physical activity schedule } & Flexible (ref) & \\
\hline & General & \\
\hline & Elaborate & \\
\hline \multirow[t]{3}{*}{ Consult structure } & Individual (ref) & \\
\hline & In a group with 5 other people who participate in the lifestyle intervention program & \\
\hline & In a group with 10 other people who participate in the lifestyle intervention program & \\
\hline \multirow[t]{3}{*}{ Expected outcome } & No weight loss but feeling fitter & 0 \\
\hline & Weight loss of 5 kilograms and feeling fitter & 5 \\
\hline & Weight loss of 10 kilograms and feeling fitter & 10 \\
\hline \multirow[t]{6}{*}{ Money $^{a}$} & Financial reward of 75 euro for 3-6 months & 0.75 \\
\hline & Financial reward of 150 euro for 3-6 months & 1.50 \\
\hline & Financial reward of 225 euro for 3-6 months & 2.25 \\
\hline & Out-of-pocket costs of 75 euro for 3-6 months & -0.75 \\
\hline & Out-of-pocket costs of 150 euro for 3-6 months & -1.50 \\
\hline & Out-of-pocket costs of 225 euro for 3-6 months & -2.25 \\
\hline \multirow[t]{2}{*}{ Receiving dummy } & Need to pay out-of-pocket costs & 0 \\
\hline & Receiving a financial reward & 1 \\
\hline
\end{tabular}

a) within one choice task both situations had a financial reward or out-of-pocket costs for the "money" attribute.

the costs and financial rewards was sufficient to influence behavior. The menu schedule and physical activity schedule attributes described how the goals that DM2 patients wanted to achieve concerning a healthier diet and physical activity were developed. The program participants and a lifestyle coach will compose these schedules together using either of the three following options: "flexible", "general" or "elaborate". The flexible schedules will be initiated mostly by the participants themselves, because they will set their own goals and develop their own schedule to reach those goals. Within the general schedules, a lifestyle coach will inform the participants about healthy diets and physical activity schedules. Finally, elaborate schedules will be constructed by a lifestyle coach. This coach will develop the diet or physical activity plan tailored to the wishes and needs of the patient. The fourth attribute is the consult structure attribute that describes in what group composition the consults with the lifestyle coach take place. During these consults, participants will develop their menu and physical activity schedule and discuss their progress. The three possible levels of the consult attribute are "individual", "in a group with 5 other people" and "in a group with 10 other people". The final attribute is the expected outcome attribute, which describes the outcome that participants expect with respect to weight loss when the program will be completed. The levels of this attribute are: "no weight loss but feeling fitter", "5 kilograms of weight loss and feeling fitter" and "10 kilograms of weight loss and feeling fitter".

Before completing the choice tasks, respondents were provided with an extensive explanation of the meaning of all attributes and levels as well as an explanation on how to deal with a choice task, accompanied by an example.

A subgroup of 20 DM2 patients pilot tested a draft version of a comparable DCE as used for our study, before it was finished and disseminated among the entire sample, to test whether the wording used in the questionnaire was correct and whether the target population understood the choice tasks. Most of the pilot tests were postal questionnaires and respondents were asked to indicate which questions they did not understand and give suggestions on how the questionnaire could be improved. In addition, three think aloud pilot tests were conducted to also get information on any difficulties respondents experience while answering 
the DCE. We also asked whether they noticed a change in the choice tasks half way in the DCE. This change in the pilot study was similar to the change of the financial attribute in our DCE (changing from outof-pocket costs to financial reward scenarios or vice versa). Based on the pilot results, no changes were made to the questionnaire.

\section{Experimental design and questionnaire}

$\mathrm{N}$-Gene software was used to construct an efficient design for the DCE questionnaire. In this D-optimal design, level balance, utility balance and minimal overlap between attribute levels were optimized. It was assumed that there was no interaction between attributes [30,31]. The DCE in this study comprised of two blocks of 9 choice tasks. The first block of 9 choice tasks contained hypothetical scenarios with out-of-pocket costs for the "money" atrribute and the second block contained hypothetical scenarios with a financial reward (version 1 of the questionnaire). Participants' initial reference state or reference state induced by completing the first 9 choice tasks could cause bias. Therefore, the two blocks of 9 choice tasks were reversed in a second version of the questionnaire. The choice tasks with out-of-pocket costs and reward scenarios were clearly separated by a sentence indicating that from this point forward the "money" attribute would change compared to the previous 9 questions. To extra emphasize this change, the previous mentioned sentence was printed in a red color and underlined with a red line.

In addition to the 18 choice tasks, questions about age, gender, income, education, current physical activity levels, and questions about participants' general opinion about lifestyle programs and their intention to participate in such programs were included. Before answering the choice tasks, participants had to indicate their most preferred level of each attribute. Next to the information obtained by the DCE questionnaire, patient information (age, BMI, sex, use of medication, HbA1c values and ethnicity) from medical records was available. These data were combined for all further analyses.

\section{Statistical analysis}

N-Logit 3.0 was used to construct the panel-mixedmultinomial-logit (Panel-MIXL) models that were used for data analysis. This model takes into account the correlation between the answers given by one participant, which was necessary because each respondent completed 18 choice tasks. By using this model, bias in the attribute estimates, caused by this panel structure in the data, was prevented.

The model in equation 1 describes the utility of a specific lifestyle program based on the attributes that were included in the DCE.

$$
\begin{aligned}
U=V+\varepsilon=\beta_{\mathrm{o}} & +\beta_{1} * \text { flexible menu schedule } \\
& +\beta_{2} * \text { elaborate menu schedule } \\
& +\beta_{3} * \text { flexible } P A \text { schedule } \\
& +\beta_{4} * \text { elaborate } P \text { A schedule } \\
& +\beta_{5} * \text { consultation in groups of } 5 \\
& +\beta_{6} * \text { consultation in groups of } 10 \\
& +\beta_{7} * \text { expected outcome }+\beta_{8} * \text { money } \\
& +\beta_{9} * \text { receiving dummy }+\beta_{10} * \text { money } \\
& * \text { receiving dummy }+\varepsilon
\end{aligned}
$$

$\beta_{0}$ represents the alternative specific constant, $\beta_{1}-\beta_{8}$ are the attribute estimates that indicate the relative importance of each attribute, $\beta_{9}$ is the estimate of the dummy variable (receiving or paying money) and $\beta_{10}$ is the estimate for the interaction between money and the dummy variable. Both the constant of the model and the expected outcome attribute were included in the model as a random parameter (assuming a normal distribution). The constant was included as a random parameter, because it was expected that respondent preferences regarding lifestyle intervention programs differ a priori. The outcome attribute was also set as a random parameter, because preference heterogeneity was expected based on the large differences in baseline BMI of participants. The non-linear variables were included in the model using effects coding [32]. By means of a spline function, the part-worth utilities for all attribute levels were estimated to determine whether they should be included as continuous or effects coded parameters.

In order to study whether the impact of hypothetical out-of-pocket costs was larger than the impact of a hypothetical financial reward of the same magnitude, a spline was added to the regression model. This spline enabled to test whether the slopes of out-of-pocket costs and financial rewards differed [33]. The spline consisted of a main effect "money", a dummy variable "receiving dummy" and an interaction variable "money"receiving dummy". The value of the dummy variable was 0 in the case of out-of-pocket costs and 1 in the case of financial rewards. As a result, the "knot" was put at 0 euro. This "knot" indicated the possible bend in the regression slope of the association between hypothetical out-of-pocket costs and financial rewards and the willingness of DM2 patients to participate in a lifestyle program. As a consequence of including the spline, the effect of decreasing out-of-pocket costs on the willingness to participate is represented by the estimate of the variable "money" and since we chose to code the dummy variable 1 for receiving a financial reward, the effect of receiving a financial reward on the willingness to participate is represented by the sum of the main effect "money" and the interaction variable "money*receiving dummy". 


\section{Results}

\section{Study population}

In total 206 respondents (response rate 26.9\%) completed the questionnaire. Of this sample $53.4 \%$ completed version 1 of the questionnaire (out-of-pocket costs first, financial reward thereafter) and $46.6 \%$ completed version 2 of the questionnaire (financial reward first and out-of-pocket costs thereafter). All together, 2998 observations (i.e. choice tasks answered) were included in the analysis. Almost half of the respondents stated that a lifestyle program is useful or very useful, but only $24.8 \%$ believed that they probably or certainly wanted to participate in a lifestyle program (Table 2).

Of the respondents, $64.4 \%$ was of West-European origin and $54.1 \%$ were male. The respondents had a mean age of 61.6 (SD 11.5) years and a mean BMI of 29.9 (SD 5.4) kg/ $\mathrm{m}^{2}$. The mean HbA1c was 52.6 (SD 10.1) $\mathrm{mmol} / \mathrm{mol}$ and $81.0 \%$ used antidiabetic drugs. A non-response analysis (Table 2) showed that the age, BMI, sex and use of diabetes medication were similar between responders and non-responders. HbA1c values were significantly higher (54.6 (SD 12.2) $\mathrm{mmol} / \mathrm{mol}$ ) and the percentage of Western Europeans was significantly lower $(56.0 \%)$ among nonresponders.

\section{Comparing the effects between a hypothetical financial reward and out-of-pocket costs on the willingness to participate in a lifestyle intervention program}

Three attributes "consult structure", "expected outcome" and "money" were found to influence the willingness of DM2 patients to participate in a lifestyle program (Table 3). Since the focus of this study is on the influence of costs and financial rewards, the remaining part of the results section will only describe the results with respect to the "money" attribute.

The attribute level estimate of decreasing out-of-pocket costs is represented by the estimate of the variable "money" in Table 3 (estimate $=0.615$ ). This positive attribute level estimate (due to coding) indicates that the less people have to pay for lifestyle intervention program participation, the more willing they are to participate in such a program (Figure 2). The attribute level estimate of a financial reward is represented by the sum of the attribute level estimate of the variable "money" and the interaction estimate of "money"receiving dummy" (estimate $=0.615+$ $(-1.081)=-0.466)$. This negative estimate level indicates that the higher the hypothetical financial reward people expected to receive for program participation, the lower

Table 2 Description of the study population

\begin{tabular}{|c|c|c|c|c|c|c|}
\hline & \multicolumn{3}{|c|}{ Respondents } & \multicolumn{3}{|c|}{ Non-respondents } \\
\hline & $N$ & $\begin{array}{c}\text { Mean } \\
\text { (SD) }\end{array}$ & Percentage & $N$ & $\begin{array}{c}\text { Mean } \\
\text { (SD) }\end{array}$ & Percentage \\
\hline \multirow[t]{2}{*}{ Age (years) } & 205 & 61.6 & & 562 & 61.2 & \\
\hline & & $(11.5)$ & & & $(12.6)$ & \\
\hline Gender (male) & 205 & & 54.1 & 562 & & 52.7 \\
\hline Ethnicity (West-European origin) & 205 & & 64.4 & 562 & & 56.0 \\
\hline \multirow[t]{2}{*}{$\mathrm{HbA} 1 \mathrm{c}(\mathrm{mmol} / \mathrm{mol})$} & 194 & 52.6 & & 499 & 54.6 & \\
\hline & & $(10.1)$ & & & $(12.2)$ & \\
\hline Medication (using antidiabetic drug) & 205 & & 81.0 & 562 & & 81.7 \\
\hline \multirow[t]{2}{*}{ BMI $\left(\mathrm{kg} / \mathrm{m}^{2}\right)$} & 200 & 29.9 & & 533 & 30.4 & \\
\hline & & $(5.4)$ & & & $(5.5)$ & \\
\hline General opinion about lifestyle programs & 205 & & & & & \\
\hline Very useful & & & 14.5 & & & \\
\hline Useful & & & 34.0 & & & \\
\hline Neutral & & & 45.5 & & & \\
\hline Not so useful & & & 2.0 & & & \\
\hline Not useful at all & & & 4.0 & & & \\
\hline Intention to participate in a lifestyle program & 200 & & & & & \\
\hline Certainly not & & & 21.0 & & & \\
\hline Probably not & & & 35.1 & & & \\
\hline I do not know & & & 19.0 & & & \\
\hline Probably & & & 14.6 & & & \\
\hline Certainly & & & 10.2 & & & \\
\hline
\end{tabular}


Table 3 Attribute estimates (standard errors) of the Panel-MIXL including the spline

\begin{tabular}{|c|c|c|c|c|}
\hline Attribute & & Estimates & SE & P-value \\
\hline \multirow[t]{2}{*}{ Constant } & & -0.291 & 0.185 & 0.115 \\
\hline & SD constant & 0.939 & 0.563 & 0.095 \\
\hline \multirow[t]{3}{*}{ Menu schedule } & Flexible (ref) & -0.027 & & \\
\hline & General & -0.034 & 0.060 & 0.570 \\
\hline & Elaborate & 0.061 & 0.063 & 0.331 \\
\hline \multirow[t]{3}{*}{ Physical activity schedule } & Flexible (ref) & -0.111 & & \\
\hline & General & 0.034 & 0.057 & 0.546 \\
\hline & Elaborate & 0.077 & 0.052 & 0.142 \\
\hline \multirow[t]{3}{*}{ Consult structure } & Individual (ref) & 0.087 & & \\
\hline & In groups with 5 other patients & 0.158 & 0.059 & 0.008 \\
\hline & In groups with 10 other patients & -0.245 & 0.074 & 0.001 \\
\hline \multirow[t]{2}{*}{ Expected outcome } & & 0.059 & 0.013 & 0.000 \\
\hline & SD expected outcome & 0.091 & 0.047 & 0.051 \\
\hline Money $^{\mathrm{a}}$ & & 0.615 & 0.122 & 0.000 \\
\hline Receiving dummy & & -0.169 & 0.244 & 0.490 \\
\hline Interaction $^{\mathrm{b}}$ & & -1.081 & 0.147 & 0.000 \\
\hline Money *Receiving dummy & & & & \\
\hline
\end{tabular}

a)The estimate "money" represents the attribute level estimate of the effect of out-of-pocket costs on the willingness to participate. The less people have to pay for lifestyle intervention program participation, the more willing they are to participate in such a program (Figure 2).

b) For the effect of receiving a financial reward on the willingness to participate the estimate of the interaction variable "money*receiving dummy" is added to the main effect "money" (estimate receiving a financial reward $=0.615+(-1.081)=-0.466)$ (Figure 2 ).

their willingness to participate in a lifestyle program was (Figure 2).

Though the absolute value of the attribute level estimate for receiving a hypothetical financial reward was smaller than the absolute value of the attribute level estimate for paying hypothetical out-of-pocket costs (i.e. indication that people would react stronger to costs than to financial rewards), the difference between these absolute values of the attribute estimate levels was not significant $(P>0.05)$ (data not shown).

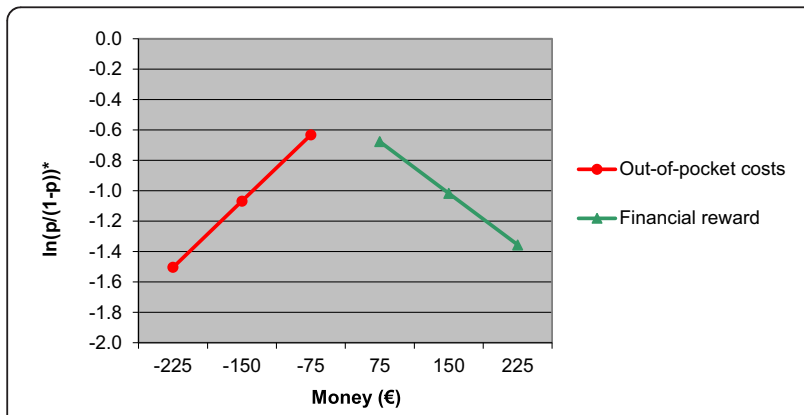

Figure 2 Influence of costs and financial rewards on the willingness to participate in lifestyle programs. Figure 2 shows that when out-of-pocket costs for lifestyle program participation increase, the willingness to participate decreases and that when financial rewards for lifestyle program completion increase, the willingness to participate also decreases. ${ }^{*} p$ is the chance that a respondent wants to participate in a lifestyle intervention program.
To study whether education, age and ethnicity influenced the association between - costs and financial rewards - and the willingness to participate, these variables were added to the model. Study results did not alter significantly upon inclusion of these variables (data not shown).

To study whether the a priori intention to participate, as expressed in the additional questions, influenced the results, an additional analysis was done, using only the data of the respondents who stated that they would probably or certainly participate in a lifestyle program (24.8\%). The results of this analysis were not significantly different from the results described above.

\section{Discussion}

This study aimed to investigate the effects of financial rewards and out-of-pocket costs on the willingness of DM2 patients to participate in a lifestyle program. Results showed that increasing out-of-pocket costs are associated with a decreasing willingness of DM2 patients to participate in a lifestyle intervention program and that, contrary to our expectations, an increasing financial reward was also associated with a decreasing willingness of DM2 patients to participate in a lifestyle intervention program. The negative association between out-of-pocket costs and the willingness to participate confirmed our expectations and is in line with previously conducted research $[1,2,25,34]$. On the other hand, the negative association 
between a financial reward and the willingness to participate was not in line with previously set expectations that an increasing financial reward would increase the willingness to participate. However, before completing the choice tasks, participants registered what the minimum amount of compensation for participation in a lifestyle program was that they wanted to receive. Also, it was asked what amount they were willing to pay for participation in a lifestyle program. In both questions, 75 euro was the amount preferred most often (62.3\% chose 75 euro as level of compensation, and $72.0 \%$ chose 75 euro as level of payment preferred most). So these results are in line with the results of our DCE.

The negative relationship found in the current study may be understood by the reciprocity of the social exchange theory [35]. According to this theory, people feel that the more they are rewarded, the more effort they should put in a relationship or work they are rewarded for. In this case, patients may feel that they should put more effort in the lifestyle intervention program to measure up to reciprocity, when the financial reward they receive gets larger. Instead of motivating people by offering a financial reward, a feeling of obligation may scare people off [36].

Another explanation could be that in most lifestyle intervention research, participants are highly motivated, while our respondents, being a cross-section of DM2 patients within a general practice setting, might be not. In order to create a scenario that may be plausible within the Dutch healthcare system, the maximum financial reward was set at 225 euro. It may be that this amount is sufficient to create a feeling of obligation to comply to a lifestyle program (reciprocity), but is too small to compensate for the efforts that are necessary for a lifestyle change. The actual relation between - costs and financial rewards - and the willingness of people (who have not yet initiated action) to participate in a lifestyle program may be that of a cosine (first a negative slope and then moving up). If this is true, and the financial reward levels included too small amounts of money, we only describe the first part of this relation, resulting in a negative slope. The financial threshold to convince these people to participate in a lifestyle program may be much higher than 225 euro, while people, who are already motivated to participate, do not need such a large incentive. However, it is not realistic to think that people would ever receive a financial reward that is much higher than 225 euro, since this would be not affordable in a healthcare setting.

Finally, it is possible that people feel like they are being explicitly controlled or monitored by a financial reward. People may react negatively to this feeling $[37,38]$.

In addition, it was expected that out-of-pocket costs would have a stronger impact on the willingness to change behavior than financial rewards. Although out-of-pocket costs tended to have a stronger impact on the willingness to participate than a financial reward, this difference in effect-size was not statistically significant. There might be a significant difference, but that might be too small to detect with this sample size. Since the difference (if existing) is small, one could question if this difference is of practical importance.

\section{Strengths and limitations}

A strength of this study was that the questionnaires contained both reward and out-of-pocket costs scenarios, so both types of choice tasks (with out-of-pocket costs and financial rewards) were completed by the same respondents. Therefore, the comparison between the effects of costs and financial rewards was not biased by patient characteristics or selective response. An additional strength, as already mentioned in the methods section, is that the position of the financial reward and out-of-pocket costs choice tasks was counterbalanced in the second version compared to the first version of the DCE. However, some limitations should be mentioned as well.

First, even after sending a reminding letter, the response rate of $26.9 \%$ was relatively low, resulting in a study population of 206 DM2 patients. However such a response rate is comparable with response rates of other DCE questionnaires sent by (e-)mail $[29,39,40]$. In addition, most published DCE's include between the 100 and 300 respondents, so our sample size falls within this range [41]. Nevertheless the relatively low response rate might influence the generalizability of our results.

Due to cooperation with four health care centers, demographic and disease specific characteristics of both respondents and non-respondents were available. Concerning age, BMI, sex and the use of medication respondents and non-respondents were comparable, but the percentage West-European people differed between the groups (64.4\% in responders and $56.0 \%$ in the non-responders). However, as ethnicity did not significantly influence the association between - costs and financial rewards - and the willingness to participate, we think that the influence of the overrepresentation of West-European responders was limited.

On the other hand, information about other factors like income, social norm, self-efficacy and attitude towards lifestyle programs that could influence the choices of participants, were not available for non-responders. Therefore, the non-response is likely to be selective, in the sense that DM2 patients who are not interested in a lifestyle program were also less likely to participate in this study. It may for instance be that patients who perceive their own lifestyle to be healthy are not interested in lifestyle programs, and therefore did not participate in this study. However, these patients would in real life probably also not participate in an actual lifestyle program, since they think they have a healthy lifestyle, and are therefore of limited interest for this 
specific study. Though different magnitudes of costs and financial rewards (ranging from -225 to 225 euro) were tested, previous research suggested that several other factors could influence the effectiveness of costs and financial rewards as well. People's attitude towards a financial reward might for example also be independently influenced by the type of behavior (simple behavior, like a once-only vaccination or complex behavior, like changing lifestyle), the socioeconomic status (SES) of the responding population, frequency of receiving a financial incentive and the moment that the incentive was given (for example at the beginning or after completion of an intervention) [42]. This last factor refers to the present-biased preferences [43]. Education was taken into account in the analysis as a proxy for SES to adjust for possible differences in results due to SES. However, the frequency and the moment that the financial incentive was given or had to be paid was not specified in this study. Since previous research showed that these two factors are also important for the effectiveness of a financial incentive and costs [42], future research should be conducted to explore these effects.

Moreover, traditionally inhabitants of The Netherlands are used to a health insurance without any co-payment for health care. Only since a few years there is a compulsory level of co-payment within the Dutch health insurance system. When the questionnaires were administered, the maximum amount of co-payment was 220 euro for all health care on a yearly basis. So people in The Netherlands are not used to paying high co-payments for health care. As a result, it may have been difficult for them to value this lifestyle program as offered within a health care setting. Therefore, our results may be less generalizable to countries with health insurance systems where people are used to high levels of co-payments for health care.

A limitation of a DCE in general is that there is limited knowledge if hypothetical choices made in a DCE reflect actual choices as made in real life. The external validity of DCE's is still under-researched [44]. Therefore, research to test for a possible difference between the influence of hypothetical costs and financial rewards on the hypothetical willingness and the participation rates of such lifestyle intervention programmes in real life, is needed.

\section{Conclusions}

This study shows that increasing out-of-pocket costs for participation in a hypothetical lifestyle intervention program are associated with a decreasing willingness of DM2 patients to participate in that program, and that, contrary to what was expected, an increasing financial reward for participation in a hypothetical lifestyle program is also associated with a decreasing willingness to participate. Increasing out-of-pocket costs may prevent people from deciding to participate in a lifestyle program. However, offering a financial reward to persuade people to participate in a lifestyle program may result in a decreasing willingness to participate in a lifestyle program as well.

\section{Abbreviations}

BMI: Body mass index; DM2: Diabetes mellitus type 2; DCE: Discrete choice experiment; GP: General practitioner; Panel-MIXL: Panel-mixed-multinomiallogit models; SES: Socioeconomic status.

\section{Competing interests}

This manuscript comprises original, unpublished data.

The authors declare that there are no conflicts of interest. This study was funded by the Strategic Research Fund (SOR) of the National Institute for Public Health and the Environment (RIVM). Sponsors were not part of the research group and therefore were not involved in conducting the research, writing the manuscript or submitting the final paper.

\section{Authors' contributions}

J.O.P.W. performed the data analysis and wrote the manuscript. J.V. prepared the questionnaire, conducted the expert interviews and focus groups, designed the DCE and critically reviewed the manuscript. G.A.W. was involved in writing the research protocol, she gave advice during the entire project and critically reviewed the manuscript. H.E.H. provided us with the patient information from the medical records and critically reviewed the manuscript. P.F.G. was involved in writing the research protocol and critically reviewed the manuscript. M.S.L was the project leader of this research project and was therefore involved in all stages of this study. All authors read and approved the final manuscript.

\section{Author details}

${ }^{1}$ National Institute for Public Health and the Environment, Centre for Prevention and Health Services Research, PO Box 1 (Internal postal code: 101), 3720 BA Bilthoven, The Netherlands. 'Division: Julius Center for Health Sciences and Primary Care, University Medical Center Utrecht, Huispost Str. 6.131, Postbus 85500, 3508 GA Utrecht, The Netherlands. ${ }^{3}$ Leidsche Rijn Julius Health Care Centers, Eerste Oosterparklaan 78, 3544 AK Utrecht, The Netherlands.

Received: 18 February 2014 Accepted: 18 August 2014 Published: 23 August 2014

\section{References}

1. Meier KJ, Licari MJ: The effect of cigarette taxes on cigarette consumption, 1955 through 1994. Am J Public Health 1997, 87(7):1126-1130.

2. Chaloupka FJ, Yurekli A, Fong GT: Tobacco taxes as a tobacco control strategy. Tob Control 2012, 21(2):172-180.

3. Wilson NA, Thomson GW: Tobacco tax as a health protecting policy: a brief review of the New Zealand evidence. N Z Med J 2005, 118(1213): No 1213.

4. Spence J, Holt N, Dutove J, Carson V: Uptake and effectiveness of the Children's Fitness Tax Credit in Canada: the rich get richer. BMC Public Health 2010, 10:356.

5. Schmidt $\mathrm{H}$ : Bonuses as incentives and rewards for health responsibility: a good thing? J Med Philos 2008, 33(3):198-220.

6. Volpp KG, Troxel AB, Pauly MV, Glick HA, Puig A, Asch DA, Galvin R, Zhu J, Wan F, DeGuzman J, Corbett E, Weiner J, Audrain-McGovern J: A randomized, controlled trial of financial incentives for smoking cessation. N Engl J Med 2009, 360(7):699-709.

7. Sigmon SC, Patrick ME: The use of financial incentives in promoting smoking cessation. Prev Med 2012, 55(Suppl):S24-S32.

8. Kahneman D, Tversky A: Prospect theory: an analysis of decision under risk. Econometrica 1979, 47(2):263-292.

9. Tversky A, Kahneman D: Loss aversion in riskless choice: a reference dependent model. Q J Econ 1991, 106(4):1039-1061.

10. Sutherland $\mathrm{K}$, Christianson JB, Leatherman S: Impact of targeted financial incentives on personal health behavior: a review of the literature. Med Care Res Rev 2008, 65(6 Suppl):36S-78S.

11. Kane RL, Johnson PE, Town RJ, Butler M: A structured review of the effect of economic incentives on consumers' preventive behavior. Am J Prev Med 2004, 27(4):327-352. 
12. Sutherland K, Leatherman S, Christianson J: Paying the patient: does it work? a review of patient-targeted incentives. 2008. ISBN: 987-1-906461-04-1.

13. Jeffery RW: Financial incentives and weight control. Prev Med 2012 55(Suppl):S61-S67.

14. Lussier JP, Heil SH, Mongeon JA, Badger GJ, Higgins ST: A meta-analysis of voucher-based reinforcement therapy for substance use disorders. Addiction 2006, 101(2):192-203.

15. Lancsar E, Louviere J: Conducting discrete choice experiments to inform healthcare decision making: a user's guide. Pharmacoeconomics 2008, 26(8):661-677

16. Ryan M, Gerard K, Amaya-Amaya M: Using Discrete Choice Experiments to Value Health and Health Care. Dordrecht: Springer; 2008.

17. Dube MC, Valois P, Prud'homme D, Weisnagel SJ, Lavoie C: Physical activity barriers in diabetes: development and validation of a new scale. Diabetes Res Clin Pract 2006, 72(1):20-27.

18. Forbes CC, Plotnikoff RC, Courneya KS, Boule NG: Physical activity preferences and type 2 diabetes: exploring demographic, cognitive, and behavioral differences. Diabetes Educ 2010, 36(5):801-815.

19. Lakerveld J, ljzelenberg W, van Tulder MW, Hellemans IM, Rauwerda JA, van Rossum AC, Seidell JC: Motives for (not) participating in a lifestyle intervention trial. BMC Med Res Methodol 2008, 8:17.

20. Nagelkerk J, Reick K, Meengs L: Perceived barriers and effective strategies to diabetes self-management. J Adv Nurs 2006, 54(2):151-158.

21. Owen K, Pettman T, Haas M, Viney R, Misan G: Individual preferences for diet and exercise programmes: changes over a lifestyle intervention and their link with outcomes. Public Health Nutr 2010, 13(2):245-252.

22. Roux L, Ubach C, Donaldson C, Ryan M: Valuing the benefits of weight loss programs: an application of the discrete choice experiment. Obes Res 2004, 12(8):1342-1351.

23. Thomas DE, Elliott EJ, Naughton GA: Exercise for type 2 diabetes mellitus. Cochrane Database Syst Rev 2006, 3, CD002968.

24. Thomas N, Alder E, Leese GP: Barriers to physical activity in patients with diabetes. Postgrad Med J 2004, 80(943):287-291.

25. van Gils PF, Lambooij MS, Flanderijn MH, van den Berg M, de Wit GA, Schuit AJ, Struijs JN: Willingness to participate in a lifestyle intervention program of patients with type 2 diabetes mellitus: a conjoint analysis. Patient Prefer Adherence 2011, 5:537-546.

26. Vijan S, Stuart NS, Fitzgerald JT, Ronis DL, Hayward RA, Slater S, Hofer TP: Barriers to following dietary recommendations in Type 2 diabetes. Diabet Med 2005, 22(1):32-38.

27. Wood FG: Ethnic differences in exercise among adults with diabetes. West J Nurs Res 2002, 24(5):502-515.

28. Krueger RA, Casey MA: Focus Groups: A practical guide for applied research. Thousand Oaks: Sage Publications, Inc.; 2000

29. Veldwijk J, Lambooij MS, van Gils PF, Struijs JN, Smit HA, de Wit GA: Type 2 diabetes patients' preferences and willingness to pay for lifestyle programs: a discrete choice experiment. BMC Public Health 2013, 13:1099.

30. Huber J, Zwerina K: The importance of utility balance in efficient choice designs. J Market Res 1996, 33(3):307-317.

31. Bliemer MCJ, Rose JM: Efficiency and sample size requirments for stated choice experiments. Washington DC: Transportation Research Board Annual Meeting; 2009

32. Bech M, Gyrd-Hansen D: Effects coding in discrete choice experiments. Health Econ 2005, 14(10):1079-1083.

33. Marsh LC, Cormier DR: Spline Regression Models. Thousand Oaks, CA: Sage Publications, Inc; 2002

34. Guimaraes C, Marra CA, Colley L, Gill S, Simpson S, Meneilly G, Queiroz RH, Lynd LD: Socioeconomic differences in preferences and willingness-topay for insulin delivery systems in type 1 and type 2 diabetes. Diabetes Technol Ther 2009, 11(9):567-573.

35. Blau PM: Exchange and power in social life. New York: John Wiley \& sons; 1964

36. Allan C, Radley A, Williams B: Paying the price for an incentive: an exploratory study of smokers' reasons for failing to complete an incentive based smoking cessation scheme. J Health Serv Res Policy 2012, 17(4):212-218

37. Kohn A: Why incentive plans cannot work. Harv Bus Rev 1993, 71(5):54-60.

38. Gneezy U, Meier S, Rey-Biel P: When and why incentives (don't) work to modify behavior. J Econ Perspect 2011, 25(4):191-210.

39. Bogelund M, Vilsboll T, Faber J, Henriksen JE, Gjesing RP, Lammert M: Patient preferences for diabetes management among people with type
2 diabetes in Denmark - a discrete choice experiment. Curr Med Res Opin 2011, 27(11):2175-2183.

40. Hauber AB, Mohamed AF, Johnson FR, Falvey H: Treatment preferences and medication adherence of people with Type 2 diabetes using oral glucose-lowering agents. Diabet Med 2009, 26(4):416-424.

41. Marshall D, Bridges JF, Hauber B, Cameron R, Donnalley L, Fyie K, Johnson FR: Conjoint analysis applications in health - how are studies being designed and reported?: an update on current practice in the published literature between 2005 and 2008. Patient 2010, 3(4):249-256.

42. Lynagh MC, Sanson-Fisher RW, Bonevski B: What's good for the goose is good for the gander. Guiding principles for the use of financial incentives in health behaviour change. Int J Behav Med 2013, 20(1):114-120.

43. O'Donoghue T, Rabin M: Doing It Now or Later. Am Econ Rev 1999, 89(1):103-124.

44. de Bekker-Grob EW, Ryan M, Gerard K: Discrete choice experiments in health economics: a review of the literature. Health Econ 2012, 21(2):145-172.

doi:10.1186/1471-2458-14-870

Cite this article as: Wanders et al:: The effect of out-of-pocket costs and financial rewards in a discrete choice experiment: an application to lifestyle programs. BMC Public Health 2014 14:870.

\section{Submit your next manuscript to BioMed Central and take full advantage of:}

- Convenient online submission

- Thorough peer review

- No space constraints or color figure charges

- Immediate publication on acceptance

- Inclusion in PubMed, CAS, Scopus and Google Scholar

- Research which is freely available for redistribution 